\title{
Production and consumption of homegrown produce and fish by noncommercial aquaponics gardeners
}

\author{
David C. Love, ${ }^{\mathrm{a}, \mathrm{b}} *$ Laura Genello, ${ }^{\mathrm{a}, \mathrm{b}}$ Ximin Li, ${ }^{\mathrm{c}}$ Richard E. Thompson, ${ }^{\mathrm{c}}$ and Jillian P. Fry a,b \\ Johns Hopkins University
}

Submitted May 22, 2015 / Revised August 18, 2015 / Accepted September 16, 2015 /

Published online December 18, 2015

Citation: Love, D. C., Genello, L., Li, X., Thompson, R. E., \& Fry, J. P. (2015). Production and consumption of homegrown produce and fish by noncommercial aquaponics gardeners. Journal of Agriculture, Food Systems, and Community Development, 6(1), 161-173. http://dx.doi.org/10.5304/jafscd.2015.061.013

Copyright (C) 2015 by New Leaf Associates, Inc.

\begin{abstract}
Aquaponics is the integration of hydroponics and aquaculture into a single food production system. The aims of this paper are to describe production practices and costs among noncommercial aquaponics gardeners, and identify factors related to homegrown food consumption using a survey. The sample size was 399 respondents from 24 countries. The median aquaponics system was 350 gallons (1,325 liters) in volume, 100 square feet (9

a Johns Hopkins Center for a Livable Future, Johns Hopkins University, Baltimore, Maryland USA.

b Department of Environmental Health Sciences, Bloomberg School of Public Health, Johns Hopkins University, Baltimore, Maryland USA.

${ }^{\mathrm{c}}$ Department of Biostatistics, Bloomberg School of Public Health, Johns Hopkins University; Baltimore, Maryland USA.

* Corresponding author: David C. Love, 615 North Wolfe Street, Room W7009; Baltimore, Maryland 21205 USA; +1-410-5027578; dlove8@jhu.edu
\end{abstract}

square meters) in size, and cost respondents US\$500 to US\$999 annually. Respondents consumed homegrown aquaponics plants far more often than they consumed fish. The primary factors that affected weekly homegrown plant consumption were location in warm climates, which allows for a longer growing season and likely lower input costs; an interest in improving diet; size of aquaponics garden; and years of experience. Respondents with high school or less education consumed homegrown fish and crops more often than those with college or graduate education, indicating that aquaponics may contribute to

\footnotetext{
Authors Note

This work was funded by the Johns Hopkins Center for a Livable Future (CLF) with a gift from the GRACE Communications Foundation, which had no role in study design, data collection, or analysis, decision to publish, or preparation of the manuscript. We would like to thank Anne Palmer and Shawn McKenzie at CLF for their review and helpful insights.
} 
community food security at the household level for these individuals. Noncommercial aquaponics gardens have significantly higher yearly costs compared to soil-based gardens, so the participants who are attracted to aquaponics (typically middleaged men with high levels of education) may not be food insecure, which weakens the case for aquaponics as a means of improving food security. Based on our findings, further research on this topic and other work to expand aquaponics to improve community food security should focus on low-cost yet productive aquaponics systems in warm climate regions and among more diverse populations.

\section{Keywords}

gardening, garden, homegrown, fish, health, aquaculture, aquaponics, food security, tilapia

\section{Introduction and Literature Review}

Aquaponics is the integration of soilless crop production (hydroponics) and aquatic animal production (aquaculture) into a single food production system. Fish are raised in tanks and their waste is broken down and converted into nutrients by bacteria. Plumbing connects tanks that hold plants and fish, so the system water can be continuously recycled. Crops such as leafy greens, tomatoes, and herbs absorb nutrients from the water, which partly cleans the water for the fish. A handful of studies of aquaponics were conducted in the 1970s, 1980s, and 1990s (Bailey, Rakocy, Cole, \& Shultz, 1997; Lewis, Yopp, Schramm Jr, \& Brandenburg, 1978; McMurtry, Nelson, Sanders, \& Hodges, 1990; Naegel, 1977; Rakocy, 1988-89; Sneed, Allen, \& Ellis, 1975; Todd, 1980; Zweig, 1986) that focused on aspects of commercial production. Since then, the field of aquaponics has expanded beyond the research and development stage, and is being practiced by farms, nonprofit organizations, community garden groups, schools, and noncommercial gardeners. In 2013, we conducted what we believe is the first large-scale survey of aquaponics practitioners and found a rapidly growing field in which noncommercial gardeners were the largest group of respondents (Love, Fry, Genello, Hill, Frederick, Li, \& Semmons, 2014). In 2013, the U.S. Census of Agriculture identified 73 commercial aquaponics operations in 21 states, with total sales between US $\$ 1.4$ and US $\$ 5.1$ million (U.S. Department of Agriculture [USDA], 2014). In the same year, our survey identified 145 commercial aquaponics operations in 38 states with harvests of 131,000 to $212,000 \mathrm{lbs}$. $(59,400$ to $96,000 \mathrm{~kg})$ of fish, 630,000 to $1,400,000 \mathrm{lbs}$. $(286,000 \mathrm{~kg}$ to $635,000 \mathrm{~kg}$ ) of plants, and total sales between US $\$ 2.5$ and US $\$ 7.1$ million, including aquaponicsrelated revenue beyond food sales, such as consulting and agrotourism (Love, Fry, Genello, Hill, Frederick, Li, \& Semmons, 2014).

Businesses marketing aquaponics kits and supplies make claims about the benefits of aquaponics, including self-provisioning, disaster preparedness, food sovereignty, food safety, and/or as a small business. For example, Friendly Aquaponics says, "You've come to the right place if you: want to reduce your food bill and save money; want to get control of your food, and always have safe food; want to make a good living from growing food for others" (Friendly Aquaponics, n.d., "Free Food!" para. 2-5). Nelson + Pade markets a small aquaponics kit to "seriously supplement your family's food supply" (Nelson + Pade, n.d., "Home Garden," para. 1), medium-size kits that are "great for home food production and big enough that you'll likely have extra to share with friends or family" (Nelson + Pade, n.d., "Family Plus," para. 1) and larger kits that are "enough to provide fresh fish and vegetables to a family, with extra to sell at a farm stand or local farm market" (Nelson + Pade, n.d., "Family Farm Market," para. 1). The Aquaponic Source sells aquaponics kits with a logo including the phrase "control your food," and, in case of disasters, a promise that gardeners will have "household food security no matter what happens" (Bernstein, 2015).

The purpose of our research was to learn more about noncommercial aquaponics production and practices from practitioners in order to determine the amount of food produced and understand how it is used, and to compare noncommercial aquaponics to soil-based gardens. Although noncommercial aquaponics practitioners outnumber commercial growers (Love et al., 2014), there has been little research focusing specifically on this category 
of aquaponics operation. In addition, this is an important area of research because there may be parallels between aquaponics and other forms of gardening, specifically in terms of aspects of gardening that promote health, nutrition, exercise, food security, and other social and ecological benefits. An estimated 43 million households in the United States had food gardens in 2009 (National Gardening Association [NGA], 2009). Research has shown that gardening improves life satisfaction and provides other psychological benefits (Kaplan, 1973; Waliczek, Zajicek, \& Lineberger, 2005). For the elderly, gardening helps with managing dementia and provides physical activity (Caspersen, Bloemberg, Saris, Merritt, \& Kromhout, 1991; Simons, Simons, McCallum, \& Friedlander, 2006). For children, gardens represent an opportunity for hands-on learning and can augment nutrition programs (Robinson-O'Brien, Story, \& Heim, 2009). A wide range of health, nutritional, and social benefits have also been well described for community gardens (Draper \& Freeman, 2010; McCormack, Laska, Larson, \& Story, 2010; Poulsen et al., 2014). Health promotion aspects of community gardens have been identified by studies in Baltimore (Corrigan, 2011), Denver (Teig, Amulya, Bardwell, Buchenau, Marshall, \& Litt, 2009), upstate New York (Armstrong, 2000), and Philadelphia (Blair, Giesecke, \& Sherman, 1991).

Several studies have focused on consumption of fruits and vegetables from home gardens or community gardens (Alaimo, Packnett, Miles, \& Kruger, 2008; Blair et al., 1991; NGA, 2009; Kortright \& Wakefield, 2011; Litt, Soobader, Turbin, Hale, Buchenau, \& Marshall, 2011; Nanney, Johnson, Elliott, \& Haire-Joshu, 2007), which can serve as a yardstick for comparison with consumption of crops grown by aquaponics. Home gardens also impact food security by promoting food accessibility, diversity of fresh produce, and healthy diets (Kortright \& Wakefield, 2011). Additionally, individuals with home gardens (Litt et al., 2011) and community garden plots (Alaimo et al., 2008) eat more fruits and vegetables than non-gardeners, independent of whether the food was homegrown or purchased.

The objective of this study was to analyze survey data on noncommercial aquaponics gardeners that describes this group's farming practices and spending, and to identify factors related to homegrown food consumption. We then modeled factors involved in the consumption of aquaponics-grown fish and plants and compared the findings to literature on soil-based gardens. We also discuss current and potential roles of noncommercial-level and commercial aquaponics regarding household and community-level food security.

\section{Methods}

We conducted an online survey to better understand the production methods, experiences, and demographics of aquaponics practitioners in the U.S. and internationally. The authors, along with partner organizations, distributed the survey using a chain sampling method, also called "snowball sampling," in which participants help recruit other participants using their own social networks. This approach was particularly useful in identifying hard-to-reach individuals. The survey began on June 25, 2013, and closed on October 1, 2013, hosted on Qualtrics.com (Provo, Utah). The inclusion criteria for the survey was as follows: respondents must be at least 18 years old, able to read English, have completed the entire survey, and have operated and maintained an aquaponics system in the previous 12 months. Descriptive statistics about aquaponics operations (including commercial, noncommercial, and educational operations) as well as survey methods and the codebook have been published elsewhere (Love et al., 2014).

The present study analyzes a subset of the survey data (399 of 1,084 total respondents) to ask specific questions about noncommercial aquaponics gardeners, factors related to homegrown food consumption, and their relationship to food security. The inclusion criteria for this study were that in the previous 12 months respondents must have practiced aquaponics not as their primary occupation; not sold aquaponics-raised plants or fish; not received payment for consulting, design, or equipment sale of aquaponics systems; and responded to the survey with their personal activities with aquaponics (i.e., not on behalf of an organization or company).

Survey data (Qualtrics survey software) were 
exported and analyzed in Excel and STATA, and figures were produced in Prism (version 5, GraphPad). Significance for statistical tests was set at an alpha of 0.05. Error was reported as standard deviation. In order to quantify possible statistical associations between product consumption and various factors, we performed statistical tests ( $\mathrm{t}$-test and chi-square) on the outcomes for plant consumption (respondents who ate homegrown plants at least once per week versus less than once a week) and fish consumption (respondents who ate homegrown plants at least once per month versus less than once per month) with all the continuous and categorical covariates obtained from the survey.

We examined variables that were statistically associated with homegrown plant and fish consumption on a weekly and monthly basis, respectively, using bivariate analyses. These variables were then considered for inclusion in the multivariable logistics regression models fitted separately for plant and fish consumption. The final model for plant consumption incorporated a set of variables involving respondent knowledge, beliefs, years of experience, and their garden physical factors, such as size and climate zone.

\section{Results}

Survey Responses. In total, 1,084 completed the online survey, and 399 respondents met the inclusion criteria for the current study as noncommercial aquaponics gardeners.

Demographics. Table 1 presents the demographics of the survey respondents. Seventeen percent of respondents were female, and the mean age of all respondents was $48 \pm 13$ years old. Most respondents $(88 \%)$ had more than a high school level of education and were relatively new to aquaponics. Roughly a third of respondents had been practicing aquaponics for less than one year, and nearly all respondents $(96 \%)$ had less than or equal to 5 years of experience practicing aquaponics. The majority of respondents $(78 \%, N=304)$ lived in the United States. The rest lived in 23 other countries, ranked by number of respondents: Australia ( $n=44)$, Canada $(n=7)$, United Kingdom $(n=4)$, India $(n=3)$, Italy $(n=3)$, Philippines $(n=3)$, Spain $(n=3)$, China $(n=2)$, Malaysia $(n=2)$, Panama $(n=2)$, and a single respondent from Aruba, Botswana, Brazil, Greece, Netherlands, New Zealand, Puerto Rico, Saint Martin, South Africa, Sweden, Thailand, Trinidad, and Venezuela.

\section{Motivation for Practicing Aquaponics.}

Respondents were asked about their personal motivation for participating in aquaponics. On a five-point Likert scale, the typical respondent agreed or strongly agreed that "growing my own food," "improving my health," "improving the health of my community," and "environmental sustainability" were motivating factors for their aquaponics gardening. Respondent interests relative to each other were assessed using correlation

Table 1. Demographics of Survey Respondents

\begin{tabular}{lrr}
\hline Characteristics & N & $\%$ \\
\hline Overall & 399 & \\
\hline Gender & 325 & $81 \%$ \\
$\quad$ Male & 66 & $17 \%$ \\
Female & 8 & $2 \%$ \\
$\quad$ Do not wish to specify & & \\
\hline Age, year & 31 & $8 \%$ \\
$18-29$ & 75 & $19 \%$ \\
$30-39$ & 101 & $26 \%$ \\
$40-49$ & 104 & $27 \%$ \\
$50-59$ & 61 & $16 \%$ \\
$60-69$ & 19 & $5 \%$ \\
$70+$ & & \\
\hline Education & 59 & $15 \%$ \\
Graduate degree & 288 & $73 \%$ \\
College degree or college classes & 49 & $12 \%$ \\
High school, GED, or some high school & & \\
Country & 304 & $78 \%$ \\
$\quad$ United States & & \\
\hline Aquaponics experience, years & 126 & $32 \%$ \\
$<1$ & 135 & $34 \%$ \\
$1-2$ & 74 & $19 \%$ \\
$2-3$ & 34 & $9 \%$ \\
$3-4$ & 14 & $4 \%$ \\
$4-5$ & 14 & $4 \%$ \\
$>5$ & & \\
\hline
\end{tabular}


statistics. These findings help distinguish respondents that are purely interested in personal issues or bridged personal issues with community issues.

Not surprisingly, there was a strong positive correlation between growing one's own food and improving personal health (correlation coefficient $(\mathrm{cc})=0.51, p<0.01$ ). Among respondents for whom growing their own food was a priority, there was only moderate interest in improving community health ( $\mathrm{cc}=0.28, p<0.01)$. Feeling strongly about environmental sustainability also aligned with improving community health ( $\mathrm{cc}=0.49, p<$ 0.01).

Physical Components and Investments in Aquaponics. Most respondents (75\%) housed their aquaponics garden at home (Table 2).

Respondent aquaponics systems were typically located outdoors, or sometimes located in a greenhouse (which allows for an extended growing season), or in a building (for complete climate control). Nearly all respondents designed their own aquaponics system, but occasionally respondents purchased a kit or hired a consultant to design their

Table 2. Location, Design, and Investments in Aquaponics Among Respondents

\begin{tabular}{lrr}
\hline Characteristics & N & $\%$ \\
\hline Location of aquaponics system & 75 & $19 \%$ \\
Inside a building & 133 & $33 \%$ \\
Inside a greenhouse & 5 & $1 \%$ \\
On a rooftop & 199 & $50 \%$ \\
Outdoors & 302 & $76 \%$ \\
\hline Is your aquaponics system located at your home? & \\
Yes & 376 & $94 \%$ \\
Person who designed respondent aquaponics system & \\
Self-designed & 24 & $6 \%$ \\
Purchased a kit & 18 & $5 \%$ \\
Designed by consultants & 5 & $1 \%$ \\
\hline Aquaponics-related investments (US\$) in the previous 12 & months \\
$\$ 0$ & 139 & $35 \%$ \\
$\$ 1-\$ 499$ & 90 & $23 \%$ \\
$\$ 500-\$ 999$ & 129 & $32 \%$ \\
$\$ 1,000-\$ 4,999$ & 18 & $5 \%$ \\
$\$ 5,000-\$ 9,999$ & 11 & $3 \%$ \\
$\$ 10,000-\$ 49,999$ & 6 & $2 \%$ \\
Prefer not to disclose & & \\
\hline
\end{tabular}

system. Respondent aquaponics systems were small compared to commercial aquaponics facilities: the median aquaponics system was 350 gallons $(1,325$ liters) with a footprint of $100 \mathrm{ft}^{2}\left(9 \mathrm{~m}^{2}\right)$ The median amount of money respondents spent on aquaponics systems in the previous 12 months was US $\$ 500$ to US\$999. A small fraction (8\%) of respondents spent greater than or equal to US\$5,000 in the previous 12 months. Because there are high fixed costs in starting an aquaponics garden, we compared spending between individuals who have been practicing aquaponics for less than or equal to one year versus greater than one year. We found there was no difference in annual spending between these two groups $(p=0.7)$.

Fish, Plant Production, and Consumption. Respondents raised fish and plants mainly for consumption, but also as ornamentals. Nearly threequarters of respondents raised edible species of fish, the most popular being tilapia (Table 3). The remaining 26 percent of respondents only raised ornamental fish. Some respondents $(27 \%)$ raised both ornamental fish and a species of edible fish.

Respondents raised a wide range of plants, including fruits and fruiting vegetables as well as leafy greens, herbs, and cruciferous vegetables. The median number of crops grown in the previous 12 months was seven. Tomatoes, basil, peppers, and salad greens were the most popular crops, raised by $72,65,57$, and 56 percent of respondents, respectively. Less than one-fifth of respondents $(18 \%)$ raised ornamental plants and flowers, and all but three of these respondents also grew edible crops.

Respondents were asked to report their consumption frequency of homegrown aquaponics plants and fish. Sixty-five percent of respondents ate homegrown plants at least once per week, 18 percent of respondents ate homegrown plants 1 to 3 times per month, and 10 percent ate homegrown plants less than once per month and eight percent never ate homegrown plants. Aquaponics fish were consumed far less often than plants. Sixty-four percent of respondents reported never eating the fish they raised. Fourteen percent of 
respondents ate homegrown fish 1 to 3 times per month, five percent ate homegrown fish 1 to 3 times per week, and no respondents ate homegrown fish on a daily basis. There was a striking difference in plant and fish consumption by respondent nationality (Figure $1 \mathrm{a}$ and $1 \mathrm{~b}$ ). NonU.S. respondents ate homegrown fish, and to a lesser extent homegrown plants, more frequently than their U.S. counterparts. Consumption frequency was also related to level of education. Respondents with a high school education or less composed 12 percent of the study population, yet disproportionately consumed homegrown plants on a daily basis (Figure 1c). The effect of education on consumption was more pronounced for homegrown fish (Figure 1d).

\section{Modeling}

Mathematical models help us understand the relative influence and significance of multiple factors simultaneously. We created multivariable logistic regression models for plant consumption (Table 4) and fish consumption (Table 5) to understand how factors such as climate, facility size, respondent experience, knowledge, etc., are related to consumption of homegrown foods. Below is a description of the significant factors and their relationship to the outcome of eating homegrown food.

Years of Experience. Respondents were asked the date they started their first aquaponics system. With the model, we found that respondents would eat more plant and fish if they had more years of experience with aquaponics. The odds of weekly plant and monthly fish consumption were predicted to be 1.36 and 1.68 times higher, respectively, for each one-year increase in experience.

Facility Size. Facility size is the square-foot footprint of the operation. We found that respondents were more likely to eat fish if their operation was larger. To make the size of the aquaponics facility normally distributed, the data were transformed to the log scale prior to performing any statistical analyses. The odds of monthly fish consumption were predicted to be
1.46 times greater for each one-unit increase in the log-area with the logistic model.

Water Volume. The water volume of an aquaponics system helps us understand outcomes due to the size of the operation, and larger operations can hold more water. We found that respondents would eat more plants if they had larger volume aquaponics systems. Water volume was also transformed on the log scale prior to analyses. The odds of weekly plant consumption were predicted to be 1.48 times greater per one-unit increase in the logvolume of the aquaponics system.

Improved Diet. We asked if improving health was a personal priority for aquaponics practitioners, and found that respondents would consume more homegrown plants if they wished to improve their health. The survey question was on a 5-point

\section{Table 3. Fish and Plants Raised by Respondents} in the Previous 12 Months

\begin{tabular}{|c|c|c|}
\hline Products & $\mathbf{N}$ & $\%$ \\
\hline \multicolumn{3}{|l|}{ Fish } \\
\hline Ornamental fish a & 212 & $53 \%$ \\
\hline Edible fish & 294 & $74 \%$ \\
\hline Tilapia & 173 & $43 \%$ \\
\hline Catfish & 56 & $14 \%$ \\
\hline Other animals ${ }^{b}$ & 52 & $13 \%$ \\
\hline Perch & 49 & $12 \%$ \\
\hline Bluegill & 36 & $9 \%$ \\
\hline Trout & 31 & $8 \%$ \\
\hline Bass & 12 & $3 \%$ \\
\hline \multicolumn{3}{|l|}{ Plants } \\
\hline Fruiting vegetables ${ }^{c}$ & 333 & $83 \%$ \\
\hline Head, leaf lettuce and chard & 300 & $75 \%$ \\
\hline Herbs & 296 & $74 \%$ \\
\hline Cruciferous vegetables ${ }^{d}$ & 249 & $62 \%$ \\
\hline Fruit e & 170 & $43 \%$ \\
\hline Rooting vegetables ${ }^{f}$ & 161 & $40 \%$ \\
\hline Ornamental plants and flowers & 71 & $18 \%$ \\
\hline Other $\mathrm{g}$ & 36 & $9 \%$ \\
\hline
\end{tabular}

a koi, goldfish, tropical fish

${ }^{b}$ crayfish, prawns, yabbies, etc.

c peppers, tomatoes, beans, cucumber, squash, eggplant, etc.

d collard greens, kale, cabbage, broccoli, cauliflower, bok choi, etc.

e strawberries, melons, etc.

$f$ beets, carrots, onions, etc.

g corn, celery, etc. 
Likert,where agree or strongly agree corresponds to improving health as a personal priority. The logistic model predicts that aquaponics farmers who indicated that improving health was one of their motivations for practicing aquaponics were 2.48 times more likely to consume aquaponics plants on a weekly basis than those who did not consider improving health to be a personal priority. Respondent views on improved health were not a significant factor used in predicting fish consumption.

Figure 1. Consumption of Homegrown (a) Plants and (b) Fish by Country, and Consumption of (c) Plants and (d) Fish by Level of Education

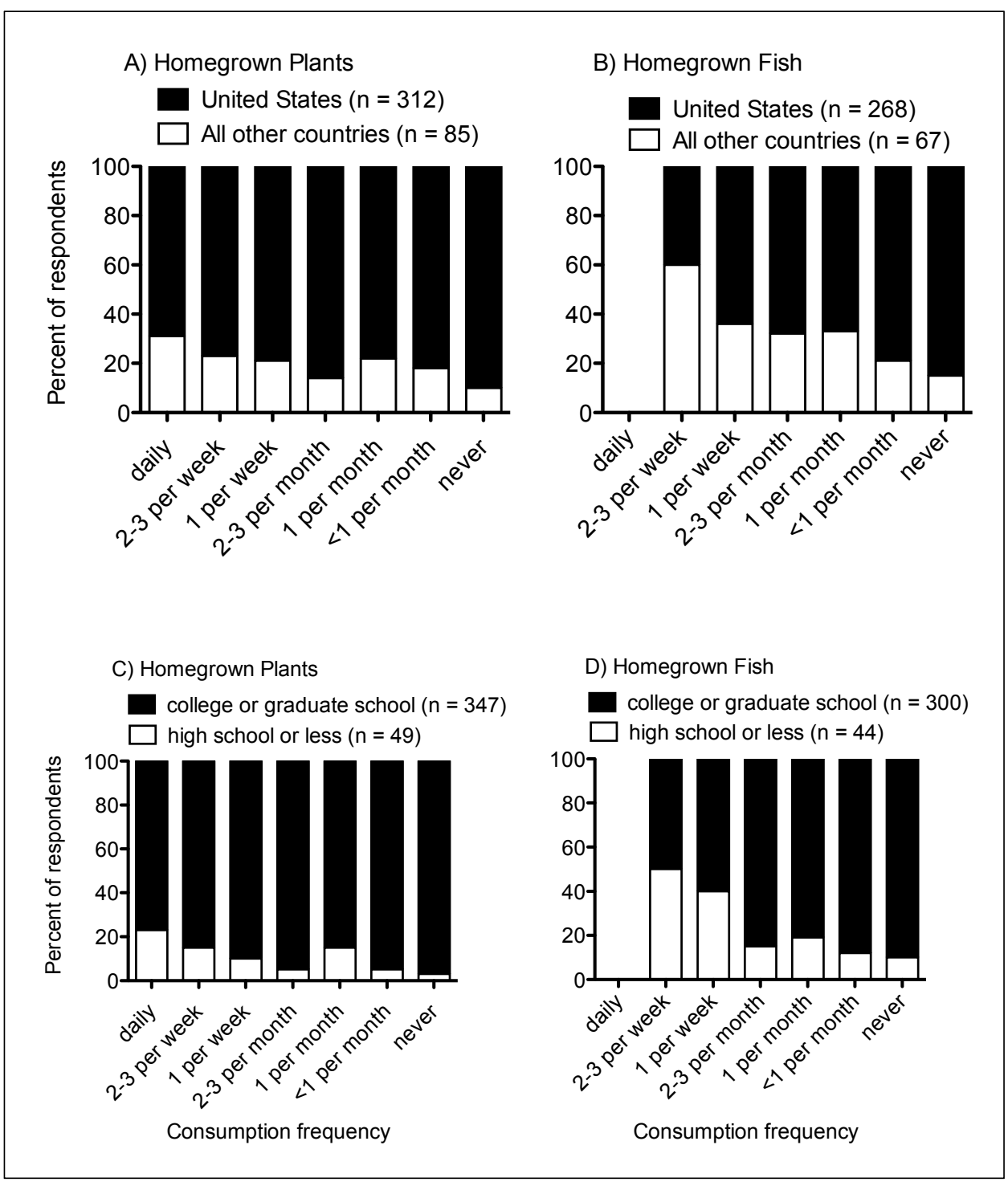

USDA Climate Zone. We expect plants to grow better in regions with milder winters, and we found that respondents would consume more plants if they live in regions with mild winters. The USDA designates climate zones called plant hardiness zones as measured by the average annual minimum winter temperature, and we identified the climate zone for each respondent by overlaying their zip code onto USDA climate zone maps using GIS software. We created three climate zone categories: areas with a mean minimum winter temperature below $-10^{\circ} \mathrm{F}$ were classified as regions with severe winters (USDA plant hardiness zones $1-5)$, areas with a mean minimum winter temperature between $-10^{\circ} \mathrm{F}$ and $20^{\circ} \mathrm{F}$ (USDA plant hardiness zones 6-8) were classified as regions where the winters are less severe, and areas with a mean minimum winter temperature greater than $20^{\circ} \mathrm{F}$ (USDA plant hardiness zones 913) were combined into a region classified as having nonsevere winters. The results from the model shows that people in the nonsevere winter and less-severe winter regions are 5.08 and 4.83 times more likely, respectively, to consume plants on a weekly basis than people in the severe winter region.

Edible Fish. This was a binary variable indicating whether or 
not the farmer raised an edible fish species as listed in Table 3 during the past 12 months. If a respondent raised ornamental fish, in addition to or in place of edible fish, then they were less likely than other respondents to consume aquaponics fish product. Not surprisingly, the odds of monthly fish consumption for people who raised edible fish was 5.92 times larger than those who did not raise these species.
Table 4. Factors Affecting Weekly Aquaponics Plant Consumption

\begin{tabular}{lccc}
\hline Weekly Plant Consumption & Odds Ratio & $P$ value & 95\% Confidence Interval \\
\hline Years of Experience & 1.36 & 0.015 & $1.06-1.75$ \\
\hline Area (log sq. ft.) & 1.48 & $<0.001$ & $1.22-1.80$ \\
\hline Improved diet & 2.48 & 0.013 & $1.22-5.06$ \\
\hline USDA plant hardiness zone a & & & \\
$\quad$ Severe Zone (1-5) & 1.00 & & \\
Less Severe Zone (6-8) & 4.83 & 0.010 & $1.45-16.05$ \\
$\quad$ Nonsevere Zone (9-13) & 5.08 & 0.009 & $1.50-17.24$ \\
\hline
\end{tabular}

a The climatic zones for non-U.S. respondents were converted to the USDA plant hardiness zone scale.

\section{Table 5. Factors Affecting Monthly Aquaponics Fish Consumption}

\begin{tabular}{lccc}
\hline Monthly Fish Consumption & Odds Ratio & P value & 95\% Confidence Interval \\
\hline Years of Experience & 1.68 & 0.000 & $1.31-2.17$ \\
Water Volume & 1.46 & 0.010 & $1.08-1.95$ \\
Edible Fish & 5.92 & 0.101 & $0.708-49.5$ \\
Ornamental Fish & 0.255 & 0.001 & $0.112-0.579$ \\
Knowledge & 2.76 & 0.005 & $1.362-5.57$ \\
\hline
\end{tabular}

Ornamental Fish. This was a binary variable indicating whether or not the respondent raised ornamental fish in the past 12 months. Given that the types of fish the gardener raised will most likely affect fish consumption from aquaponics operations, the logistic regression model predicts that farmers who raised ornamental fish were less likely to consume fish they raised on a monthly basis than those who had not raised ornamental fish in the past year (odds ratio $=0.255$ ).

Knowledge. This was a binary variable evaluating the knowledge and ability required to maintain an aquaponics operation, and was based on the average overall responses to aquaponics-related knowledge and skills questions in the survey. These questions were given with a 5-point Likert scale, where agree or strongly agree corresponds to being knowledgeable about or having the ability to perform the operation(s) described in each statement. Based on the logistic regression model, the extent of monthly fish consumption was predicted to be 2.76 times higher for people more knowledgeable about aquaponics-related operations than those with less knowledge. Knowledge was not a significant variable for predicting plant consumption.
Comparison of Noncommercial Aquaponics Gardens to Soil-Based Gardens. Aquaponics gardens and soil-based gardens share many similarities: size $\left(\sim 100 \mathrm{ft}^{2}\right.$ or $\left.9 \mathrm{~m}^{2}\right)$, location (at home), and the types of crops (NGA 2009) (Table 6). We found that aquaponics gardens contained more leafy greens than soil gardens, most likely because the nitrogen-rich water promotes leaf growth, and because fruit trees and some rooting crops are not suited for aquaponics.

There were several areas that differentiate our study respondents from the average gardener: the sex of gardeners, age and experience, and level of spending (Table 6). Women constitute slightly more than half of U.S. gardeners, but only 17 percent of respondents in our study. Aquaponics respondents were slightly younger and had less experience than the average gardener. Aquaponics respondents had higher rates of college education compared to the average U.S. household gardener, and aquaponics gardeners spent significantly more money annually on gardening activities.

\section{Comparison of noncommercial aquaponics} gardens and commercial aquaponics operations. Noncommercial aquaponics gardens were 
Table 6. Comparison of Noncommercial Aquaponics Gardening to Soil-based Gardening

\begin{tabular}{lcc}
\hline Characteristic & $\begin{array}{c}\text { Aquaponics (present } \\
\text { study) }\end{array}$ & $\begin{array}{c}\text { Soil-based (NGA, } \\
\text { 2009) a }\end{array}$ \\
\hline \% female & $17 \%$ & $54 \%$ \\
\hline Education & & \\
$\quad$ College, some or degree & $88 \%$ & $79 \%$ \\
\hline Experience (median years) & 2 & 4 \\
\hline Garden size $\left(\mathrm{ft}^{2} \mid \mathbf{~ m}^{2}\right)$ & $100.3 \mid 9.3$ & $96 \mid 8.9$ \\
\hline Annual cost & US $\$ 500-U S \$ 999$ b & US\$70 \\
\hline Located at home & $76 \%$ & $91 \%$ \\
\hline Vegetables grown & & \\
Tomatoes & $72 \%$ & $86 \%$ \\
Cucumbers & $41 \%$ & $47 \%$ \\
Sweet peppers & $57 \%$ & $46 \%$ \\
Beans & $36 \%$ & $39 \%$ \\
Salad greens & $56 \%$ & $17 \%$ \\
Collard greens & $42 \%$ & $9 \%$ \\
Kale & $31 \%$ & $3 \%$ \\
\hline
\end{tabular}

a NGA (2009) used a stratified random sample of over 2,000 U.S. household gardens and reported values weighted to the U.S. population.

$\mathrm{b}$ The median interval reported by respondents.

significantly smaller in size, had less money invested annually in operations, and used different methods than commercial aquaponics operations (Table 7). Both commercial and noncommercial aquaponics operations attract visitors, with the number of visitors commensurate with the size of

\section{Table 7. Comparison of Noncommercial and Commercial Aquaponics}

\begin{tabular}{|c|c|c|}
\hline $\begin{array}{l}\text { Characteristic } \\
\text { (median values) }\end{array}$ & $\begin{array}{c}\text { Noncommercial } \\
\text { aquaponics gardens } \\
\text { (present study) }\end{array}$ & Commercial aquaponics farms a \\
\hline Farming method & media bed $\mathrm{b}$ & raft c \\
\hline Tank volume (gal. I liters) & $350 \mid 1,325$ & $7,000 \mid 26,500$ \\
\hline Facility size ( $\left.\mathrm{ft}^{2} \mid \mathrm{m}^{2}\right)$ & $100 \mid 9$ & $2,900 \mid 269$ \\
\hline Fish harvests (lb./yr. | kg/year) & unknown & $100-499 \mid 45-226$ \\
\hline Plant harvests (Ib./year | kg/year) & unknown & $500-999 \mid 227-453$ \\
\hline Annual gross sales & US\$0 & US $\$ 5,000-$ US $\$ 9,999$ \\
\hline Annual spending & US $\$ 500-U S \$ 999$ & US $\$ 10,000-$ US $\$ 49,000$ \\
\hline Annual no. visitors & $1-24$ & $100-499$ \\
\hline
\end{tabular}

a Data from Love et al., 2014, using data from commercial farms with sales of fish or plants in 2013.

b Media beds contain soilless media, such as expanded shale or clay pebbles, and are used to grow crops with a flood-and-drain irrigation method.

${ }^{c}$ Rafts refer to polystyrene or other materials used for buoyancy to float crops in tanks of water about 0.2 to 0.4 meters deep. Crops are then planted inside net-pots, which are inserted into holes in the floating rafts. the operations. Currently, commercial aquaponics gardens resemble other small farms regarding size, sales, use of direct marketing, and labor force (Love, Fry, Li, Hill, Genello, Semmens, \& Thompson, 2015).

\section{Discussion}

The purpose of this research was to better understand noncommercial aquaponics gardeners, describe their growing practices and costs, and identify factors related to homegrown food consumption. We modeled factors that relate to homegrown food consumption for fish and plants in order to identify opportunities for enhanced consumption of homegrown foods. We compared noncommercial aquaponics gardens to an existing survey of soil-based gardens to assess ways this new form of agriculture differs from standard approaches. To understand the scope and scale of noncommercial gardens, we compared our findings to our own published data on commercial aquaponics operations. Finally, we examined the current and potential roles of noncommercial and commercial aquaponics in regard to household and community-level food security.

In the survey, we assessed respondent motivations for practicing aquaponics, which were primarily to raise their own food, enhance environmental sustainability, and improve their personal health and the health of their community. Homegrown plants were consumed on a weekly basis by about two-thirds of 
respondents; weekly consumption was more likely among individuals interested in improving their health, and who had a larger area under cultivation and had more experience with aquaponics. Consumption of homegrown crops does not necessarily cause improved health outcomes; however, improved access to produce is a contributing factor to improving health. Respondents were more likely to eat their crops if they lived in mild to warm climates, a finding that occurred on a gradient of USDA plant hardiness zone groups (zones 1-5; 6-8; 9-13). The association with climate is not surprising because shorter, milder winters allow for longer growing seasons.

An unexpected finding was that aquaponicsraised fish were not regularly consumed by most respondents, making it difficult to substantiate claims about noncommercial aquaponics gardening as a means to improve self-provisioning of animal protein. These findings differ from the marketing claims used by some businesses to sell aquaponics kits. There are several possible reasons why this may be the case. First, over a quarter of respondents raised only ornamental fish. Second, fish can take a year or more to reach harvestable size, and about a third of respondents had less than one year of aquaponics experience, indicating that the fish may not have reached harvestable size. Third, aquaponics systems can have low stocking densities of fish and still achieve high plant yields, which makes these enterprises geared towards crop production. In a survey of commercial aquaponics operators, fish were harvested in lower amounts than vegetables (Love et al., 2015). Fourth, respondents may lack the skills or be unwilling to slaughter, clean, and cook fish, while in comparison fruits and vegetables can be eaten raw or minimally processed. We did not assess respondent competency in fish processing or cooking, which may be a barrier to preparing homegrown fish.

Two subsets within the study population ate more homegrown fish than the average respondent. Non-U.S. respondents ate more homegrown fish than U.S. respondents, suggesting differences in food culture between U.S. and non-U.S. respondents. Respondents with a high school degree or less education consumed homegrown fish more frequently than respondents with more education. Education can serve as a proxy for income (De Gregorio \& Lee, 2002), and respondents with less education may have fewer economic resources and more incentive to consume homegrown fish for dietary needs. Noncommercial aquaponics may be contributing to household food security for these individuals; however, the typical respondents were middle- aged men with high levels of education and an interest in technology and/or engineering, who may not be food insecure.

We compared noncommercial aquaponics to soil gardens, because soil gardening has a wide range of benefits such as promoting physical and mental health, nutrition, and food security (Blair et al., 1991; Kortright \& Wakefield, 2011; Waliczek et al., 2005). We found that individuals practicing aquaponics were more likely to be male, have higher levels of education, to be less experienced gardeners, and to invest ten times more money than soil gardeners. The same types of crops were raised in soil gardens and aquaponics gardens (with the exception of fish), and plots of land were roughly the same size. Because aquaponics does not require soil, these gardens can easily be located inside a building; nearly one fifth of respondents located their aquaponics garden indoors. Operators of aquaponics systems may find advantages in the greater flexibility of system placement and the potential for year-round production. The higher costs in aquaponics can be attributed to the capital costs needed to purchase equipment such as tanks, pumps, and other materials, and recurring costs for fish, fish feed, and soilless planting media. The recurring costs in aquaponics are not insignificant; we did not observe a difference in average annual spending between individuals who had operated a system for less than or equal to one year and who had for one or more years. More research is needed to understand why noncommercial aquaponics gardeners are willing to spend more than soil-based gardeners on similar-sized gardens, and whether these costs produce added benefits, aside from the attraction of using a new technology. Interestingly, despite an abundance of aquaponics kits available on the market, only 11 percent of respondents used a kit or a consultant to design their system. The technology and the process of system design may be an attraction for many aquaponics 
gardeners. The provisioning of food is not the only reason to garden; soil-based gardeners rarely produce enough for self-sufficiency (Kortright \& Wakefield, 2011) and spending on grocery bills is similar between gardeners and non-gardeners (Nanney et al., 2007).

We found that commercial aquaponics operations were an order of magnitude larger, more costly to maintain, and more productive than noncommercial operations. From a community food-security perspective, larger commercial operations may be better suited than personal gardens for producing and distributing food. Commercial aquaponics is still an emerging field, however, with perhaps 150 farms in the U.S. (Love et al., 2015). We estimate that about 20 acres ( 8 hectares) are in commercial aquaponics production in the U.S. (Love et al., 2015), which is 0.0003 percent of the 6.6 million acres ( 2.7 million hectares) in U.S. vegetable production in 2013 (USDA-ERS, 2013). There is a similarly dramatic difference between commercial aquaponics fish harvests and total U.S. aquaculture harvests. At the current scale, commercial aquaponics is not making a substantial impact on community food security. Two case studies, and our survey, indicate that the profitability of many, but not all, commercial aquaponics operations is in question (Love et al., 2015; Tokunaga, Tamaru, Ako, \& Leung, 2015). Scaling up aquaponics would require effort from a variety of disciplines, including training to develop a workforce knowledgeable in hydroponics and aquaculture, outreach to city and state officials who may not be knowledgeable on how to permit or regulate aquaponics facilities, and a cohesive set of industry guidelines or best management practices. New business models may be needed to identify what factors enable an operation to succeed.

Given the real challenges in expanding aquaponics beyond household-level operations including the considerable effort required to build necessary capacity — aquaponics should be weighed against other approaches for improving community food security, such as community gardening, using SNAP/EBT cards at farmers markets, and other activities that increase access to healthy food choices. For groups seeking to site commercial aquaponics in a community, several factors need to be considered, such as climate zone, economic sustainability of the business, zoning laws, availability of skilled and unskilled labor, knowledge, the cultural relevance of the products, and for whom the products are intended (local consumers versus consumers in distant markets). In addition to commercial farms and noncommercial gardens, a third approach practiced by nonprofit organizations such as Growing Power in Milwaukee (Growing Power, n.d.) seeks to provide education, job training, and food security within a community using aquaponics. The Center on Disability Studies at the University of Hawaii runs the Aquaponics Workforce Development program (University of Hawaii, n.d.), another example of job training using aquaponics. In some cases, nonprofits are engaging in commercial sales; studying the community benefits of these types of organizations is beyond the scope of this paper, however.

Our research does have some limitations. Due to the snowball sampling method and nonrandom sampling used to reach this population, we may have missed some aquaponics gardeners, and our findings may not be representative of all people practicing aquaponics at the household level. In particular, it is likely that we did not capture the entire population of non-U.S. aquaponics gardeners in a representative manner.

\section{Conclusions}

Aquaponics is a niche form of gardening practiced in the United States and internationally. Aquaponics gardeners are motivated by the desire to grow their own food, improve their health and the health of their community, and improve environmental sustainability. Most aquaponics respondents consumed homegrown plants on a weekly basis, while homegrown fish consumption among respondents was infrequent. Non-U.S. respondents and respondents with less education ate homegrown fish more frequently than the average respondent. Noncommercial aquaponics gardeners are similar in many ways to soil-based gardeners, and their gardens contribute to household dietary intake; however, two major differences are higher yearly costs and fewer women practicing aquaponics compared to soil-based gardens. For lower-income households who participate in noncommercial 
aquaponics, they may be contributing to community food security at the household level by attracting a different audience to home gardening and providing a soil-less means of self-provisioning produce and fish. At the community level, commercial aquaponics is more appropriate for producing larger amounts of food, but this form of food production faces certain barriers and the current scale of commercial aquaponics production is very small compared to soil-based agriculture and other forms of aquaculture.

\section{References}

Alaimo, K., Packnett, E., Miles, R. A., \& Kruger, D. J. (2008). Fruit and vegetable intake among urban community gardeners. Journal of Nutriton Education and Behavior, 40(2), 94-101. http://dx.doi.org/10.1016/j.jneb.2006.12.003

Armstrong, D. (2000). A survey of community gardens in upstate New York: Implications for health promotion and community development. Health and Place, 6(4), 319-327. http://dx.doi.org/10.1016/S1353-8292(00)00013-7

Bailey, D. S., Rakocy, J. E., Cole, W. M., \& Shultz, K. A. (1997). Economic analysis of a commercial-scale aquaponic system for the production of tilapia and lettuce. Paper presented at the Tilapia Aquaculture: Proceedings of the Fourth International Symposium on Tilapia in Aquaculture, Orlando, Florida.

Bernstein, S. (2015, September 9). Secure your food source [Blog post]. Retrieved from Aquaponic Source website: http://theaquaponicsource.com/ service/household-food-security/

Blair, D., Giesecke, C. C., \& Sherman, S. (1991). A dietary, social and economic evaluation of the Philadelphia urban gardening project. Journal of Nutrition Education, 23(4), 161-167. http://dx.doi.org/10.1016/S0022-3182(12)81191-5

Caspersen, C. J., Bloemberg, B. P., Saris, W. H., Merritt, R. K., \& Kromhout, D. (1991). The prevalence of selected physical activities and their relation with coronary heart disease risk factors in elderly men: The Zutphen Study, 1985. [Clinical trial comparative study research support, non-US gov.]. American Journal of Epidemiology, 133(11), 1078-1092.

Corrigan, M. P. (2011). Growing what you eat: Developing community gardens in Baltimore, Maryland. Applied Geography, 31(4), 1232-1241. http://dx.doi.org/10.1016/j.apgeog.2011.01.017
De Gregorio, J., \& Lee, J. W. (2002). Education and income inequality: New evidence from crosscountry data. Review of Income and Wealth, 48(3), 395416. http://dx.doi.org/10.1111/1475-4991.00060

Draper, C., \& Freeman, D. (2010). Review and analysis of the benefits, purposes, and motivations associated with community gardening in the United States. Journal of Community Practice, 18(4), 458-492. http://dx.doi.org/10.1080/10705422.2010.519682

Friendly Aquaponics. (n.d.). Welcome to Friendly Aquaponics! Retrieved December 10, 2015, from https://declara.com/collection/e203438a-2962467a-8460-ff82fb02360c/post/eed8cbbb- $988 \mathrm{~b}-$ 4280-a9bc-fc8b62c2f7d6

Growing Power. (n.d.). About. Retrieved December 10, 2015, from http://www.growingpower.org/about/

Kaplan, R. (1973). Some psychological benefits of gardening. Environment and Behavior, 5(2), 145-162. http://dx.doi.org/10.1177/001391657300500202

Kortright, R., \& Wakefield, S. (2011). Edible backyards: A qualitative study of household food growing and its contribution to food security. Agriculture and Human Values, 28(1), 39-53. http://dx.doi.org/10.1007/s10460-009-9254-1

Lewis, W. M., Yopp, J. H., Schramm, H. L., Jr., \& Brandenburg, A. M. (1978). Use of hydroponics to maintain quality of recirculated water in a fish culture system. Transactions of the American Fisheries Society, 107(1), 92-99. http://dx.doi.org/10.1577/ 1548-8659(1978)107<92:UOHTMQ>2.0.CO;2

Litt, J. S., Soobader, M.-J., Turbin, M. S., Hale, J. W., Buchenau, M., \& Marshall, J. A. (2011). The influence of social involvement, neighborhood aesthetics, and community garden participation on fruit and vegetable consumption. American Journal of Public Health, 101(8), 1466-1473. http://dx.doi.org/10.2105/AJPH.2010.300111

Love, D. C., Fry, J. P., Genello, L., Hill, E. S., Frederick, J. A., Li, X., \& Semmens, K. (2014). An international survey of aquaponics practitioners. PLOS One. 9(7):e102662. http://journals.plos.org/ plosone/article?id=10.1371/journal.pone.0102662

Love, D. C., Fry, J. P., Li, X., Hill, E. S., Genello, L., Semmens, K., \& Thompson, R. E. (2015). Commercial aquaponics production and profitability: Findings from an international survey. Aquaculture, 435, 67-74. http://dx.doi.org/ $\underline{10.1016 / \text { i.aquaculture.2014.09.023 }}$ 
McCormack, L. A., Laska, M. N., Larson, N. I., \& Story, M. (2010). Review of the nutritional implications of farmers' markets and community gardens: A call for evaluation and research efforts. [Research support, non-US gov. review]. Journal of the American Dietetic Association, 110(3), 399-408. http://dx.doi.org/10.1016/j.jada.2009.11.023

McMurtry, M. R., Nelson, P. V., Sanders, D. C., \& Hodges, L. (1990). Sand culture of vegetables using recirculated aquacultural effluents. Applied Agricultural Research, 5(4), 280-284.

Naegel, L. C. A. (1977). Combined production of fish and plants in recirculating water. Aquaculture, 10(1), 17-24. http://dx.doi.org/10.1016/00448486(77)90029-1

Nanney, M. S., Johnson, S., Elliott, M., \& Haire-Joshu, D. (2007). Frequency of eating homegrown produce is associated with higher intake among parents and their preschool-aged children in rural Missouri. [Research support, N.I.H., extramural]. Journal of the American Dietetic Association, 107(4), 577-584.

http://dx.doi.org/10.1016/i.jada.2007.01.009

National Gardening Association [NGA]. (2009). The impact of home and community gardening in America. South Burlington, Vermont: Author. Retrieved from http://www.nativeseeds.org/pdf/2009Impact-of-Gardening-in-America-White-Paper.pdf

Nelson + Pade, Inc. (n.d.). Home and school systems. Retrieved August 2015 from http:/ /aquaponics. $\mathrm{com} /$ page/home-and-school-systems

Poulsen, M. N., Hulland, K. R. S., Gulas, C. A., Pham, H., Dalglish, S. L., Wilkinson, R. K., \& Winch, P. J. (2014). Growing an urban oasis: A qualitative study of the perceived benefits of community gardening in Baltimore, Maryland. Culture, Agriculture, Food and Environment, 36(2), 69-82. http://dx.doi.org/10.1111/cuag.12035

Rakocy, J. E. (1988-89). Hydroponic lettuce production in a recirculating fish culture system. Island Perspectives, 3, 4-10. Retrieved from http://dloc.com/CA01300009/00001

Robinson-O'Brien, R., Story, M., \& Heim, S. (2009). Impact of garden-based youth nutrition intervention programs: A review. [Meta-analysis research support, US gov., P.H.S. review]. Journal of the American Dietetic Association, 109(2), 273-280. http://dx.doi.org/10.1016/i.jada.2008.10.051
Simons, L. A., Simons, J., McCallum, J., \& Friedlander, Y. (2006). Lifestyle factors and risk of dementia: Dubbo study of the elderly. [Research support, non-US gov.]. Medical Journal of Australia, 184(2), 68-70.

Sneed, K., Allen, K., \& Ellis, J. E. (1975). Fish farming and hydroponics. Aquaculture and the Fish Farmer, 1(1), 18-20.

Teig, E., Amulya, J., Bardwell, L., Buchenau, M., Marshall, J. A., \& Litt, J. S. (2009). Collective efficacy in Denver, Colorado: Strengthening neighborhoods and health through community gardens. Health and Place, 15(4), 1115-1122. http://dx.doi.org/10.1016/j.healthplace.2009. $\underline{06.003}$

Todd, J. (1980). Dreaming in my own backyard. Journal of the New Alchemists, 6, 108-111.

Tokunaga, K., Tamaru, C., Ako, H., \& Leung, P.-S. (2015). Economics of small-scale commercial aquaponics in Hawaii. Journal of the World Aquaculture Society, 46(1), 20-32. http://dx.doi.org/10.1111/jwas.12173

U.S. Department of Agriculture. (2014). Census of Aquaculture (2013), 2012 Census of Agriculture, 3(Part 2). Retrieved from http://www.agcensus.usda.gov/ Publications/2012/Online Resources/Aquaculture Laquacen.pdf

U.S. Department of Agriculture, Economic Research Service. (2013). U.S. per capita use of fresh and processing vegetables, dry pulse crops, and potatoes; cash receipts; U.S. vegetable trade. Vegetables and Pulses Yearbook (Data No. 89011). Retrieved from http://www.ers.usda.gov/dataproducts/vegetables-and-pulses-data/yearbooktables.aspx

University of Hawaii. (n.d.). Aquaponics Workforce Development. Retrieved December 10, 2015, from http://www.hawaiiaquaponicsworkforce.com/

Waliczek, T. M., Zajicek, J. M., \& Lineberger, R. D. (2005). The influence of gardening activities on consumer perceptions of life satisfaction. HortScience, 40(5), 1360-1365.

Zweig, R. D. (1986). An integrated fish culture hydroponic vegetable production system. Aquaculture Magazine, 12(3), 34-40. 